\title{
Effect of Social Media on Nepali Consumer Purchase Decision
}

\author{
Rajeswor Neupane \\ Assoc. Prof. Nepal Commerce Campus, T.U.
}

\begin{abstract}
Social media has significant role on purchasing decision of buyer. The objective of this research paper is to understand how social media network influence on purchasing decision of consumer. A structured, self-administered questionnaire were distributed among 75 people of Baneshwor, Kathmandu. Out of them, 60 questionnaire were used for analysis. There was 31 male and 29 female participants. The findings showed that both male and female preferred online services (Facebook, Youtube, Instragram, Twiter etc) for social connection. On the basis of result it could be recommended that online marketers should clearly understand the application of social media to promote their products keeping their present consumers as well as attracting more potential customers.
\end{abstract}

Keywords: Social Media, Purchasing Decision, E-Word Of Mouth, Virtual World.

\section{Introduction}

Nowadays social media has been playing a dominant role in marketing communication process. With the advancement of information technology, print and electronic media has been moving to social media. Social media marketing is a completely new way of communication with the consumer. The user of traditional print and electronic way of marketing has been pursuing an alternative social life style. The printed and persuasive mass communication has been shifting day by day to social media networking. The main reason of this dramatic change is invention and massive use of World Wide Web. The user of www can be a message writer and can also disseminate his/her content across the globe virtually without any investment.

Social media marketing puts consumer back to the center of the business world and provides marketers a new set of tools to interact with consumers and to integrate them into the brands through innovative ways. It is the contemporary style of marketing as it concentrates on opening new horizons for marketers in order to promote a product or service as compared to conventional media (Prasath P \& Yelgamathem A., 2018)

In the present era, almost all companies are using social media as a tool for advertising and promoting their products and services, making online sales, attracting new potential customers, connecting with current buyers and sellers, brand support, contact business and so on. Also, with the availability of modern digital phone, it become very easier and faster for users, buyers and consumers to connect with each other. They always use social media an exchange their opinions, views, feelings, attitude towards usage of products and services. Moreover, social media also provides opportunity to consumers to compare price, quality, features, services and usability of products and services offered by different companies of same kind. (Rafiq Y \& Javeid U, 2014)

In the context of marketing, companies throughout the globe are constantly seeking new ways to reach consumers. They have understood the power of social media networking and they are developing their marketing strategies by incorporating feedback of their consumer on social media. 


\section{Literature Review}

Nowadays, there is social media that influence the perception, opinion, and attitude of common people. Some of the related studies are observed below to understand the impact of social media on consumer buying decision.

On line social networks (Facebook, Myspace, Twiter, Youtube, Virtual communities), where individuals as members, construct public profiles to share their knowledge and experiences, to post information about themselves and have contact with others who exchange and share similar interests (Chunge, Lee, 2010) Social networks are defined to be websites which link millions of users from all over the world with same interests, views and hobbies. Blogs, Youtube, Myspace, Faebook are examples of social media that are popular among all level of consumers. (Sin, et all, 2012)

\section{Conceptual Framework}

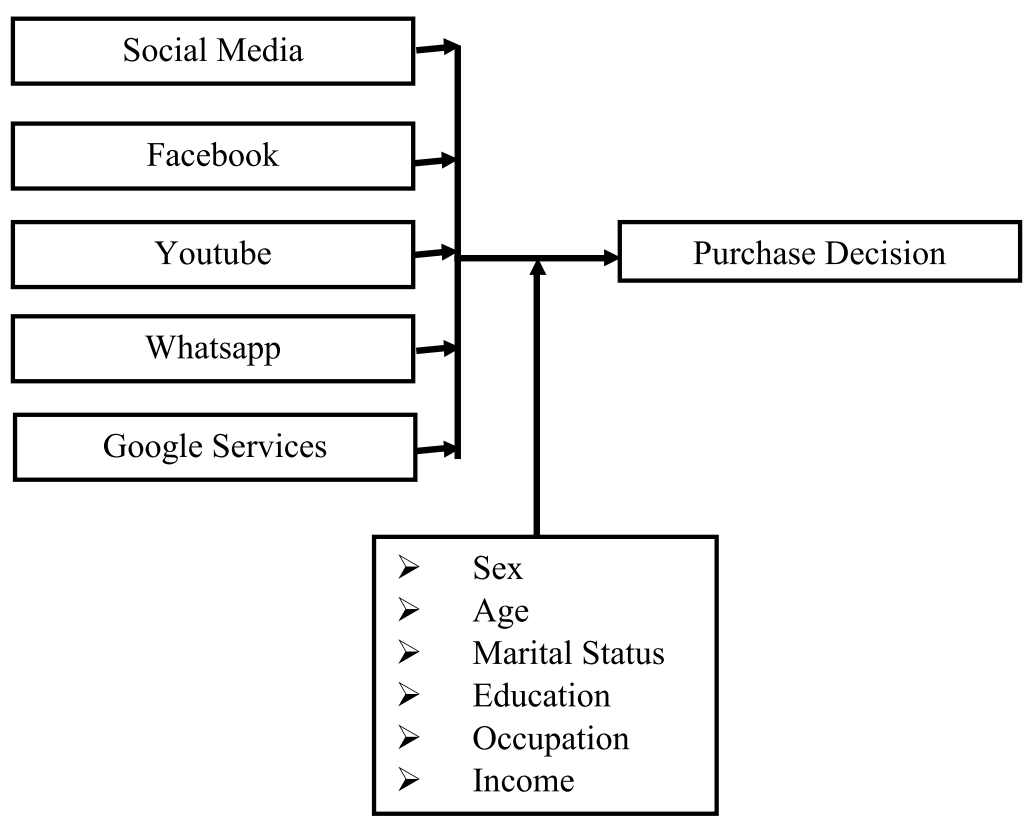

Social media websites provide an opportunities for business engage and interact with potential consumers, encourage increase sense of intimacy and build all-important relationships with potential consumers (Mersey, et all, 2010). The consumers that usually buy from online are young, working in a company, most of them are females and has at least an account on social network (Elisabeta Ioanas \& Ivona, 2014).

Abdel Qurder, (2015) revealed that the effect of social media on buying decision of customers using internet. There were 524 students of Al-Quasim University who participated in the study. Descripted and analytical techniques were applied to obtain the results and tried to develop the relationship between variables under the research study. It had been found from the exchange of information, evaluations and social connectivity had strong effect on purchasing decisions and consumers.

Bhalla (2015) had performed research on "Facebook Advertising Lifeline for small Business". He revealed how consumer exchange his/her views about products using, Facebook during shopping process. This study was based on 1000 US individuals who were aged from 18-29 years and preferred to buy products and services from local stress/business houses. The study findings suggested that about $80 \%$ of respondents did digital searching before going to do shopping physically. There were $62 \%$ adults who reported that Facebook was more reliable for searching small business before visiting store individually, followed by pinterest $12 \%$ and twitter $11 \%$. In addition to this, $54 \%$ of participants responded that they engaged with 
Facebook advertisement at least once before purchasing [product from local business houses. Finally, it had been found from results that restaurants and food stuff business considered as leading business as it was highly ranked $38 \%$ by respondents.

Consumers belong or admire different online groups generally and those groups are able to change their purchasing decision behavior (Solomen, et all, 2010). According to Evans et all (2009) joint decision making is defined as, consumers make their purchase decisions based on information that they received through mass media (e.g., advertising, newspaper, television comment but nowadays, online social networks can have paner to effect consumers' purchase decision (East R, Wright M \& Vanhuele M, 2008).

Word of mouth communication is a main part of online communication where consumers exchange and share their knowledge, opinions and experiences and has an impact on consumers; purchasing decisions. The online communities are flexible and may be based on a used range of cultural and social interests (Brown, et all, 2007). Online word-of-mouth is cheaper, faster and more effective than the other marketing tools (Dellarocas, 2003)

Schiffman, et., all (2008) concluded that reference group could categorized in to different types among them virtual community was one of the most important type. The exchange of knowledge, experiences and opinions of each individual within the group could help the product or service either sell faster or fail. Different social network groups were providing information for consumers to make them the right purchase decision.

Moreover, Hajli (2014) said due to incredible expansion of social networks and websites, mostly studies have focused consumer's behavior research by considering views and opinions of consumers on these sites. Sharma and Rehman (2012) have examined that positive and negative E-WOM about company, brand or product have significant impact on sale, image, and particularly purchasing behavior of consumers. Similarly, Wang et al. (2012) explored that online buyer socialization through different chat groups also impact on buying decision in two ways: Firstly recommended by friends directly and secondly by involvement in product

\section{Purpose of the Study}

The main purpose of this study is to analyze the effect of social media among purchase decision of consumer of Kathmandu Metropolitan City.

\section{Methods and Materials}

This study has been designed using descriptive and analytical approach. A structured and selfadministered questionnaire was prepared after seeking the advice from professional experts, consumers and consultants. The questionnaires were distributed among 85 randomly selected people in Baneshwor area of Kathmandu. Out of 85 respondents, only 60 questionnaires were finalized and processed. The questionnaires having missing information have been discarded. The data has been analyzed by using MS Excel. To analyze data frequency distribution were used.

It has been recorded that there were 31 (approximately 51\%) male and 29 (approximately 49\%) female. The respondents demographic characteristics were recorded on the basis of age, marital status, education, occupation and income. Since the main focus of the study is to make comparison between customers of Baneshwor, Kathmandu selected to analyze role of social media networking on buying decisions. Six important factors has been used to get the data and information usage pattern of internet and social media, the type of social media platforms popularly used by the consumers, the purpose behind the use of social media, the type of products consumers are inclined to buy on social media and the level of awareness while buying the products online on the basis of views, comments and opinions about products and the influence of digital marketing on the social media users. The detailed results have been discussed below. 
Silver Jubilee Issue - 2019

Table 1

Use of Internet and Social Media

\begin{tabular}{lcccc}
\hline & Very Less & Often & Frequently & Total \\
\hline Male & $8(25.8)$ & $9(29.03)$ & $14(45.16)$ & $31(100)$ \\
Female & $6(20.68)$ & $11(37.93)$ & $12(41.38)$ & $29(100)$ \\
Total & $14(23.33)$ & $20(33.33)$ & $26(43.33)$ & $60(100)$ \\
\hline
\end{tabular}

Source: Opinion survey 2019

The above table has been categorized under very less, often and frequently. $45.16 \%$ of Male selected frequently option, $29.03 \%$ selected often and $25.8 \%$ selected very less. Similarly, $41.38 \%$ of female selected frequently option, $37.93 \%$ of female selected often and $20.68 \%$ of female chose very less. It has been revealed from results that maximum percentage of male and female use internet and social media networking frequently, they were recorded $45.16 \%$ and $41.38 \%$ respectively. It can be inferred that a large portion of male and female agreed to have been devout users of Social Media Networking.

Table 2

Types of Social Media being used in General

\begin{tabular}{lcccccc}
\hline & Facebook & Youtube & Whatsapp & Google Services & Others & Total \\
\hline Male & $7(22.58)$ & $11(35.48)$ & $5(16.13)$ & $6(19.35)$ & $2(6.45)$ & 31 \\
Female & $8(27.58)$ & $9(31.03)$ & $2(6.89)$ & $7(24.14)$ & $3(10.34)$ & 29 \\
Total & $15(25)$ & $20(33.33)$ & $7(11.67)$ & $13(21.67)$ & $5(8.33)$ & 60 \\
\hline
\end{tabular}

Source: Opinion Survey 2019

The above table has been categorized by taking under account the type of social Media generally being used by the people being surveyed. A large portion of male and female respondents had been found to be using Youtube (33.33\% of total) followed closely by Facebook in second (25\% of total) and Google services $(21.67 \%)$ rounding up the top three. Other popular media like Whatsapp and Other Media had $11.67 \%$ and $8.33 \%$ users respectively.

From the table, it was observed that a large portion of both male and female opted to use Youtube as the primary medium of socialization. The trend of usage of Social Media for interaction and socialization across the surveyed demographic remained more or less the same for both male and female population.

Table 3

Purpose of Social Media Usage

\begin{tabular}{llllll}
\hline & Entertainment & Social & Commercial & Others & Total \\
\hline Male & $12(38.71)$ & $11(35.48)$ & $5(16.129)$ & $3(9.67)$ & 31 \\
Female & $8(27.57)$ & $12(41.38)$ & $7(24.14)$ & $2(6.89)$ & 29 \\
Total & $20(33.33)$ & $23(38.33)$ & $12(20)$ & $5(8.33)$ & 60 \\
\hline
\end{tabular}

Source: Opinion Survey 2019

From the table above, it could be observed that $38.71 \%$ of males admitted to using Social Media for entertainment purposes while $41.38 \%$ of females chose to use social media for socializing and interaction purposes. It can be referenced that large portion of male population showed that social media could be viewed as a source of entertainment whereas the large number of female population viewed it as a source of socialization. This difference might be because of a myriad of reasons such as the lifestyle, living standard and social stigma as well as the evolution of social media as a whole, where the differing view of its user interpreted its identity in different ways. 
Table 4

Products and Services preferred

\begin{tabular}{lcccccc}
\hline & Clothes/ Shoes & Electronic Devices & Book/ Magazine & Tickets & Others & Total \\
\hline Male & $9(29.03)$ & $11(35.48)$ & $2(6.45)$ & $1(3.23)$ & $8(25.806)$ & 31 \\
Female & $10(34.48)$ & $8(27.58)$ & $5(17.24)$ & $4(13.79)$ & $2(13.79)$ & 29 \\
Total & $19(31.67)$ & $19(31.66)$ & $7(11.67)$ & $5(8.33)$ & $10(8.33)$ & 60 \\
\hline
\end{tabular}

Source: Opinion Survey 2019

From the table it was revealed that $35.48 \%$ of male purchased electronic device, $29.03 \%$ purchased clothes and shoes, $25.81 \%$ purchased other items, $6.45 \%$ purchased books/ magazines and $3.23 \%$ purchased tickets online. Similarly, $34.48 \%$ of female purchased Clothes or Shoes online while $27.58 \%$ purchased electronic items, $17.24 \%$ purchased books/ magazines and $13.79 \%$ purchased tickets and 13.79 purchased other items not categorized online.

It shows that the maximum percentage of male population (35.48\%) percentage used the Internet (Social Media) to buy the electronic devices while the maximum percentage of female population (34.48\%) used the social media for buying clothes/ shoes. While the trend decision of what to buy seemed to be based on the perception and preference, the general trend showed that the marketers could utilize different strategies for their marketed brands based on gender.

Table 5

Read comments, views and opinions about products

\begin{tabular}{lcccc}
\hline & Not at all & Sometimes & Frequently & Total \\
\hline Male & $5(16.13)$ & $17(54.83)$ & $9(29.03)$ & 31 \\
Female & $4(13.79)$ & $7(24.14)$ & $18(62.06)$ & 29 \\
Total & $9(15)$ & $24(40)$ & $27(45)$ & 60 \\
\hline
\end{tabular}

Source: Opinion Survey 2019

The above table categorized the general trend of online purchase made by the surveyed population on the basis of their behavior prior to buying products online. It was found that $54.83 \%$ of male population read comments, views and opinions about the products sometimes before making the purchase of the particular product while $62.06 \%$ of female population frequently read comments, views and opinions regarding the product prior to buying them online.

Thus it can be concluded that despite popular belief, female were found to be more aware of the reviews about the product by other consumers that they intend to buy when compared to their male counterparts who only researched about the product based on the comments and views of other consumers sometimes.

\section{Table 6}

Influence of Pop-ups, Banners and Floating videos

\begin{tabular}{lcccc}
\hline & No & To some extent & To more extent & Total \\
\hline Male & $8(25.81)$ & $18(58.06)$ & $5(16.13)$ & 31 \\
Female & $3(10.34)$ & $10(34.48)$ & $16(55.17)$ & 29 \\
Total & $11(18.33)$ & $28(46.67)$ & $21(35)$ & 60 \\
\hline
\end{tabular}

Source: Opinion Survey 2019

The above table was formulated on the basis of views provided by the surveyed demographics who present their opinion on different strategies adopted by online marketers for influencing people about their 
products and brands online. Based on the survey, the data collected was tabulated. Based on the tabulated data, $58.06 \%$ of male respondents agreed to have been influenced to some extent, by the Pop-ups, banners and floating videos online to buy the products online. Meanwhile $55.17 \%$ of female demographics admitted to have been influenced by the marketers' strategies online to greater extent while buying the products online.

While it could be argued that significant number of female population were greatly influenced by the marketing strategies, the number of male population admitting to be influenced was not insignificant either. Thus it can be concluded that maximum number of male and female demographics agreed that digital way of marketing was more effective and efficient while comparing with traditional marketing technique.

\section{Conclusion}

This research has shed some light on the changing trend in not just marketing and advertisement but also a tectonic shift in social structure and level of awareness in people regardless of the gender of the surveyed demographics. Nowadays, majority of people have started using social media for various purposes ranging from entertainment and socialization to consumer oriented business model. There are numerous social media platforms catering to a large no. of people across the world for communication and interaction in cheaper, faster and easier manner (Rafiq et al 20). Because of this, most people are using social media and networks more and more to get connected with each other. This surge in the number of users has encouraged more and more manufacturers, marketers and sellers to effectively use the social media to promote their products encourage customers to purchase their products, services and ideas, increasing brand awareness, loyalty, trust and ultimately increasing profitability. The meteoric rise of online whole-seller such as Alibaba and ecommerce sites like Amazon, Flipkart, Daraz.com and other Social media based retailers on Facebook has been a testament to that. Based on the a consumer-focused business model, many organizations such as these have been able to build on their marketing and established a system where they can effectively get customer feedback easily and effectively and develop new marketing strategies accordingly. This all has been aided by their ability to reach customers, most of whom use social media on a regular basis.

This study is very important as it significantly contributes to understand how social media influences the choice, attitude and behavior of buying decisions of citizens of Nepal. Various comparisons have shown that there is difference in usage pattern of social media among men and women which may be due to different lifestyle choices and/or living standard among other things. Finally it is suggested that marketers should adopt advanced digital marketing tools while effectively focusing on consumers on social media for establishing brand identity and encouraging brand loyalty as these methods are not just cheap and easy but they have a potential to reach the customers in a way old fashioned and traditional marketing techniques can never reach.

\section{References}

Abdel-qader, M. (2015). The role of social networks in influencing the purchasing decision of the consumer via the internet. The Jordanian Journal of Business, Vol. 11 (1).

Bhalla, R. (2015). Facebook advertising: the social commerce lifeline for small businesses, Retrieved from www.godigitalmarketing.com

Brown J., Amanda J. B., and Nick L. (2007). Word of mouth communication within online communities: conceptualizing the online social network, Journal of Interactive Marketing, Vol. 21 (21), 2-20.

Dellarocas, C. (2003). The digitization of word of mouth: promise and challenges of online feedback mechanisms, Management Science Vol. 4 (2) 272.

East R., Wright, M., Vanhuele M. (2008). Consumer behaviour: applications in marketing. London: Sage Publication Ltd.

Elishabeta, I., and Ivona, (2014). Social media and its impact on consumer's behavior. International Journal of Economic Practices and Theories, Vol. 4 (2 
Evans, M., Jamal A., and Foxall, G. (2009). Consumer behaviour. New York: John Wiley \& Sons Ltd.

Hajli, M. N. (2014). A study of the impact of social media on consumers. International Journal of Market Research. Vol. 56, 387-404.

Sharma, S., and Asad, R. (2012). Assessing the impact of web 2.0 on consumer purchase decisions: Indian perspective: The International Journal of Technology Marketing. Vol. 2, 125-139.

Mercy, et., al., (2010), The effects of social media marketing on online consumer behavior. International Journal of Business and Management, Vol. 8, (14).

Perumal, P., and Yoganathen, A. (2018). Influencing of social media marketing on consumer buying decision making process. Slis Student Research Journal, Vol.1

Rafiq, Y., and Javeid (2014). Impact of social media on purchasing decision of consumer, Retrieved from https://www.academia.edu/36585596/

Schiffman, L.G., Kanuk, L.L., and Hansen, H. (2008). Consumer behaviour: European outlook. India: Prentice Hall.

Sin, et., al., (2012). Social media and its impact on consumers behavior, International Journal of Economic Practices and Theories, Vol. 4 (2).

Solomon, M., et. al., (2010). Consumer behavior buying: European perspective. Financial Times Press.

Wang, X., et al., (2012). Social media peer communication and impacts on purchase intentions: a consumer socialization framework. J Interactive Marketing. Vol. 26, (4), 198-208. 
